\title{
EVA... A HISTÓRIA CONTINUA...
}

\author{
EVE... THE TALE GOES ON...
}

Edna Maria F. S. Nascimento

UNIFRAN - Universidade de Franca e

UNESP - Universidade Estadual Paulista/Araraquara

Resumo: Tendo por base, principalmente, o "esquema passional canônico" do ciúme proposto por Fontanille (Jalousie. 2003), analisamos os triângulos amorosos que se constituem no conto "Desenredo", de Guimarães Rosa, em torno de um único ator, ardilosamente denominado Livíria, Rivília, Irlívia, Vilíria.

Palavras-Chave: esquema passional canônico, ciúme, ator, Guimarães Rosa.

Abstract: Based on mainly the "passional canonical scheme" of the jealousy proposed by Fontanille (Jalousie, 2003), we analyzed the loving triangles that are constituted in the tale "Desenredo" of Guimarães Rosa around an only actor, captiously denominated Livíria, Rivília, Irlívia, Vilíria.

Keywords: "passional canonical scheme", jealousy, actor, Guimarães Rosa.

O tempo é que é a matéria do entendimento.

(ROSA, J.G. Tutaméia, 1967, p. 139)

No pequeno conto "Desenredo", de apenas três páginas, do livro Tutaméia de Guimarães Rosa, é narrado, como em algumas "estorinhas" desse mesmo livro, um caso de amor bem-sucedido.

Mas antes do final feliz, vejamos como o narrador nos conta a história de Jó Joaquim. A denominação desse ator lembra-nos a afirmação de Guimarães Rosa: "Nome e homem" (Tutaméia, 1967, 108). Jó é uma personagem bíblica que, embora exposta a diferentes provações - deixa de ser rico, perde os filhos, é atingido na carne por uma doença incurável e contagiosa e é isolado numa fossa de dejetos - vive na expectativa de recuperar o que perdera, rejeitando a imagem de um Deus cruel. A paciência de Jó tem um saldo positivo; Deus lhe dá 
novos filhos e ele volta a ser rico. (BRUNEL, 2000, p. 531) Etimologicamente Jó significa $o$ molestado, o atribulado, o que geme, o perseguido. (GUÉRIOS, 1981, p. 151)

O Jó do sertão mineiro não é o mesmo da Bíblia, já tem no nome o acréscimo de um outro antropônimo, Joaquim denominação que provém de Ioakhin e significa Javé levanta, restabelece, Javé efetuará, levará a cabo ou o que fez parar o sol. (GUÉRIOS, 1981, p. 151)

Podemos observar que, etimologicamente, o antropônimo Jó contém em germe um programa narrativo disfórico, enquanto o nome Joaquim prevê uma narrativa eufórica.

Estabelecendo a relação nome/homem, o narrador, em um primeiro momento, salienta os semas que caracterizam o novo Jó que, não esqueçamos, é também Joaquim: "Jó Joaquim, cliente, era quieto, respeitado, bom como o cheiro da cerveja. Tinha o para não ser célebre." (ROSA. 1967, p. 38)

A estabilidade, a calma e o anonimato de Jó Joaquim ficam ameaçados por um simples porém, pequena conjunção adversativa que já transformou a vida de muita gente. Pergunta o narrador: "Com elas quem pode, porém?" (ROSA, 1967, p. 38)

O próximo passo é a figurativização de Jó Joaquim como Adão, personagem bíblica seduzida por Eva que o leva a cometer o pecado de comer o fruto proibido. Estando Adão-Jó Joaquim gozando do seu descanso que até aquele momento fora eterno, nasce Eva que, como comenta o narrador, pode chamar-se Livíria, Rivília ou Irlívia. Vejamos por que o papel temático de traidora da confiança de Deus, que na bíblia era recoberto pelo lexema Eva, em "Desenredo" não tem uma única denominação, mas pode ser revestido pelas três formações anagramáticas mencionadas.

A afirmação rosiana citada, "Nome e homem", serve também para Livíria, Rivília ou Irlívia, a Eva do sertão mineiro que é "Antes bonita, olhos de viva mosca, morena e pão" (ROSA, 1967, p. 38) e que estava também sujeita a uma interdição, "Aliás, casada" (ROSA, 1967, p. 38) Impedimento que não é barreira para a paixão, somente para os encontros que são às escondidas, porque, além de tudo, o marido era ciumento e a aldeia vigilante:

(...) Então ao rigor geral os dois se sujeitaram, conforme o clandestino amor em sua forma local, conforme o mundo é mundo. Todo abismo é navegável a barquinhos de papel.

Não se via quando e como se viam. (ROSA, 1967, p. 38)

Nesse triângulo, apesar de Jó Joaquim estar conjunto com o objeto amado no modo do ser, ele não perde a esperança de poder estar também conjunto no modo do parecer. Ele espera, como o Jó bíblico, que aconteça um milagre, que sua vida se transforme, podendo tornar público o seu amor e ter a amada só para ele: "Jó Joaquim, além disso, existindo só retraído, minuciosamente. Esperar é reconhecer-se incompleto. Dependiam eles de enorme milagre." (ROSA, 1967, p. 38)

Reconhecemos nesse comportamento possessivo do ator Jó Joaquim o papel patêmico de ciumento. Fontanille (Jalousie. 2003) postula que o "esquema passional canônico" do ciúme compreende diferentes fases. Uma primeira fase, a da "constituição" do sujeito apaixonado, em que se define essencialmente seu estilo rítmico, caracterizado pelo abalo e pela inquietude; uma segunda, a "disposição", onde se define sua competência principal e se instala a suspeita e a competição aberta com o rival. Jó Joaquim já é um sujeito ciumento, rivaliza-se com o marido e quer excluí-lo da vida da anagramática Livíria, Rivília ou Irlívia e acabar com esse triângulo amoroso.

Todavia, contra essa potencial felicidade temos interferências do narrador que, com máximas e comentários do tipo "o inebriado engano" (ROSA, 1967, p. 38), vai construindo outro programa narrativo que chama a atenção para o que está para acontecer. 
E, de fato, o inesperado acontece, ou como muito bem expressa o narrador "deu-se o desmastreio" (ROSA, 1967, p. 38): o marido surpreende a mulher com outro amante que não é Jó Joaquim. Instala-se uma terceira fase: a "patemização", o pivô passional propriamente dito. Há, para Jó Joaquim, a dupla perda do objeto amado, para o marido e para o amante. A possibilidade da exclusividade esvai-se, resta a falta para ele. É a típica cena da exclusão em que o rival e o objeto do ciúme são colocados dentro dela e o sujeito apaixonado fora. (FONTANILLE, 2003, p. 20) A cena transforma o estatuto do simulacro passional da perda do objeto amado, que era apenas pressentida e imaginada, e que é agora representada, ancorada claramente no sistema de referência da narração. Mas, lembremos, no caso de Jó Joaquim, a dose é dupla: ele tem rivais. Um de que ele tinha conhecimento, o marido, e que certamente preenchia a casa do rival no simulacro passional da perda do objeto amado e um que surge inesperadamente. Há aqui dois atores, o marido e o amante, que têm em relação a Jó Joaquim o mesmo papel patêmico de rival.

Temos aqui a constituição de três triângulos amorosos em que o objeto amado é a múltipla mulher Livíria, Rivília ou Irlívia.

Um triângulo ao modo do parecer que é público em que são atores a mulher, o marido e o amante. Publicamente, Jó Joaquim não tem papel patêmico nessa cena; o papel de rival é ocupado pelo outro amante. Nesse triângulo, o marido tem a seguinte reação em relação ao rival e à traidora, caracterizando a quarta fase do esquema passional de Fontanille, a "emoção", que é a manifestação pública do estado afetivo induzido: "Sem mais cá nem mais lá, mediante revólver, assustou-a e matou-o. Diz-se, também, que de leve a ferira, leviano modo" (ROSA, 1976, p. 38).

Dois outros triângulos constituem-se no modo do ser de que só têm conhecimento Jó Joaquim e a sua amada-traidora e de que participam o marido, o outro amante e Jó Joaquim, todos duplamente traídos, os dois primeiros sem conhecimento do outro rival.

A máxima rosiana, "Nome e homem", confirma-se novamente. Relata o narrador que tudo presencia, dando voz a Jó Joaquim que se pronuncia sobre Livíria, Rivília ou Irlívia: "Imaginara-a jamais a ter o pé em três estribos" (ROSA, 1976, p. 38).

Recordemos os estribos da Eva rosiana. No modo do parecer que se torna público: $1 .^{\circ}$ triângulo: Livíria, amante, marido.

No modo do ser que é privado e se constitui como duplo segredo: $2 .^{\circ}$ triângulo: Rivília, amante, Jó Joaquim; 3. ${ }^{\circ}$ triângulo: Irlívia, marido, Jó Joaquim.

Como Jó Joaquim foi pseudopersonagem nas três cenas passionais, característica atribuída pelo narrador ao amante traído, isto é, nunca desempenhou o papel patêmico de rival publicamente, a manifestação pública do estado afetivo induzido pelo ciúme, a fase da "emoção", não pode aflorar: "Jó Joaquim, derrubadamente surpreso, no absurdo desistia de crer, e foi para o decúbito dorsal, por dores, frios, calores, quiçá lágrimas, devolvido ao barro, entre o inefável e o infando" (ROSA, 1976,38).

Por fim, na última fase, a da "moralização" por meio da qual o sujeito apaixonado restabelece o espaço social, as normas e os usos em curso, cada um continua a tocar a sua vida. O marido felizardo, depois de eliminado o amante, fica com a mulher que "sempre ou ao máximo mais formosa, já sarada e sã” (ROSA, 1976, p. 39), e Jó Joaquim, o desolado, "exercitava-se a agüentar-se, nas defeituosas emoções" (Idem. Ibidem).

Se considerarmos com Greimas (1983, p. 240), conforme citação abaixo, que a paixão pára a ação para dar vazão à emoção, a paz restabelecida, a partir da fase da "moralização", deve cessar o sentir e instaurar o fazer, dando continuidade à narrativa: 


\begin{abstract}
Entretanto, é preciso sublinhar que o sintagma passional, assim construído, está longe de se constituir como um encadeamento causal. Com efeito, os elementos que o compõem não se seguem necessariamente: bem ao contrário, o desenvolvimento sintagmático da sequiência pode parar a todo momento, dando lugar, a cada parada, a um estado passional prolongado: a insatisfação se atenua em "resignação", a malevolência pode se perseverar como "hostilidade" e o desejo de vingança tornar-se estado de "rancor", sem que entretanto essa montagem passional conduza a um fazer. (tradução nossa)
\end{abstract}

Passada ou atenuada a emoção, a vida continua e "o tempo é engenhoso" (ROSA, 1967, p. 39), nos ensina mais uma máxima da narrativa: o marido da mulher que triplamente traiu, morre. Eliminados os dois rivais, um morto pelo marido traído, o marido traído morto de morte natural, "afogado ou de tifo" (ROSA, 1967, p. 39), Jó Joaquim, já curado das dores da traição, como o Jó bíblico, dos males, e envolvido de novo pela traidora Eva rosiana "sutil como uma colher de chá, grude de engodos, o firme fascínio. Nela acreditou, num abrir e não fechar de ouvidos" (ROSA, 1967, p. 39), casa-se com ela. Final feliz para essa história de amor. Jó Joaquim como o Jó da Bíblia tem a sua recompensa e entra, enfim, em conjunção pública com o objeto amado. No nível do parecer, para a população, não fora ele o traído. Ter sido excluído do primeiro triângulo, fato disfórico no dispositivo passional do ciúme, torna-se eufórico na história de Jó Joaquim; ele não é o assassino e muito menos o traído. O triângulo em que é o traído manifesta-se como um segredo entre ele e a amada. A população, conhecedora dos antecedentes de Livíria, e possivelmente tendo conhecimento dos segredos de Rivília ou Irlívia, porque "as aldeias são a alheia vigilância" (ROSA, 1967, p. 38), assiste ao desenrolar do novo caso amoroso "para feliz escândalo popular, por que forma fosse" (ROSA, 1967, p. 39).

Se não houvesse um "mas", na linha seguinte ao enunciado citado, que inicia uma nova narrativa, a forma de escândalo para a população seria a felicidade do par amoroso. Mas a pequenina conjunção adversativa prenuncia outra vez a transformação da vida de Jó Joaquim que logo se realiza. Instala-se novamente a falta como no texto bíblico, diz a narrativa rosiana: "Os tempos se seguem e parafraseiam-se" (ROSA, 1967, p. 39). Forma-se um novo triângulo, só que agora Jó Joaquim tem um papel temático público: é o marido traído. As três primeiras fases do dispositivo passional dessa vez não são manifestadas, instaura-se, de chofre, a "emoção", que é a manifestação pública do estado afetivo induzido:

Da vez, Jó Joaquim foi quem a deparou, em péssima hora: traído e traidora. De amor não a matou, que não era para truz de tigre ou leão. Expulsou-a apenas, apostrofando-se, como inédito poeta e homem. E viajou fugida a mulher, a desconhecido destino. (ROSA, 1967, p. 39)

$\mathrm{Na}$ "moralização", última fase do dispositivo passional "tudo aplaudiu e reprovou o povo, repartido" (ROSA, 1967,39).

Jó Joaquim, sabendo-se reincidente, prossegue novamente a sua vida "triste, pois que tão calado", mas "de novo respeitado, quieto" (ROSA, 1967, p. 39) Porém, ainda apaixonado, "suas lágrimas corriam atrás dela, como formiguinhas brancas" (ROSA, 1967, p. 39), seu amor configura-se como o do Jó bíblico "meditado, a prova de remorsos" (ROSA, 1967, p. 39).

Paciente como o Jó bíblico, acrescenta à sua narrativa mais uma conjunção, não mais as adversativas "porém", "mas", mas a aditiva "mais", que dá continuidade a sua história, prenunciada pela máxima: "A bonança nada tem a ver com a tempestade" (ROSA, 1967, p. 
39) Prenuncia também uma mudança a pergunta retórica, "Crível?" (ROSA, 1967, p. 39) e a referência ao herói grego Ulisses, "Sábio sempre foi Ulisses, que começou por se fazer de louco" (ROSA, 1967, p. 39), conhecido por provações pelas quais passou, principalmente quando, chegando a Ítaca, após dez anos, reencontrou Penélope, sua esposa. Passando-se por louco, Ulisses massacrou os pretendentes da sua mulher e do seu trono (BRUNEL, 2000, p. 888).

Obstinado também como o Jó bíblico, "desejava ele, Jó Joaquim, a felicidade" (ROSA, 1967, p. 39), E, para ele, a felicidade é a mulher amada. Se Jó Joaquim, enquanto Jó apenas se envolveu em programas narrativos de traição da mulher amada que se concluem com a falta, seja como amante ou marido, enquanto Joaquim que, já lembramos, significa $o$ que fez parar o sol pode dar novo rumo à sua vida. É isso que ele faz, entrega-se a "remir, redimir a mulher, à conta inteira" (ROSA, 1967, p. 39) E o narrador se pergunta: "Incrível?" (ROSA, 1967, p. 39)

A narrativa de Jó Joaquim começa a construir o desenredo que, como o nome do conto, contém muitos prefixos negativos, como des-, in-, $a$-, anti-, figurativizando a negação da situação primeira da mulher como traidora:

Nunca tivera ela amantes! Não um. Disse-se e dizia isso Jó Joaquim. Reportava a lenda e embustes, falsas lérias escabrosas. Cumpria-lhe descaluniá-la, obrigava-se por tudo. Trouxe à boca-de-cena do mundo, de caso raso, o que fora tão claro como água suja. Demonstrando-o, amatemático, contrário ao público pensamento e à lógica, desde que Aristóteles a fundou. O que não era tão fácil como refritar almôndegas. Sem malícia, com paciência, sem insistência, principalmente.

O ponto está em que o soube, de tal arte: por antipesquisas, acronologia miúda, conversinhas escudadas, remendados testemunhos. Jó Joaquim, genial, operava o passado - plástico e contraditório rascunho. Criava nova, transformada realidade, mais alta. Mais certa? (ROSA, 1967, p. 40)

A narrativa de Jó que é também Joaquim, sinônimo de Javé levará a cabo, efetuará, consegue o seu objetivo: o povo e ele próprio acreditam nessa segunda versão da história:

Pois, produziu efeito. Surtiu bem. Sumiram-se os pontos das reticências, o tempo secou o assunto. Total o transato desmanchava-se, a anterior evidência e seu nevoeiro. $\mathrm{O}$ real e válido, na árvore, é a reta que vai para cima. Todos já acreditavam. Jó Joaquim primeiro que todos. (ROSA, 1967, p. 40)

E como que a responder as duas interrogações do narrador, "Crível?" e "Incrível?", a própria traidora passa a acreditar no desenredo e volta para aquele a quem já traíra dupla e reincidentemente: uma vez como amante e outra como marido.

Nesse desenredo, a anagramática Livíria, Rivília, Irvília, nasce de novo com a denominação Vilíria. Finalmente, os triângulos amorosos estão desfeitos e Jó Joaquim pode entrar em conjunção com amada, como nos contos de fadas: "Três vezes passa perto da gente a felicidade. Jó Joaquim e Vilíria retomaram-se, e conviveram, convolados, o verdadeiro e melhor de sua vida útil.” (ROSA, 1967, p. 40)

Mas, ironicamente, o narrador remata o caso de amor com o enunciado que se inicia com a conjunção aditiva $e$, "E pô-se a fábula em ata (ROSA, 1967,"p. 40), sugerindo que essa história é uma invariante narrativa que pode ser preenchida por outros triângulos amorosos que lhe darão novas versões. 
CASA, Vol.5, n.2, dezembro de 2007

\section{Referências bibliográficas}

BRUNEL, Pierre. Dicionário de mitos literários. Rio de Janeiro: José Olympio, 2000.

CAMPOS, Geir. Pequeno dicionário de arte poética. São Paulo: Cultrix, 1978.

FONTANILLE, Jacques. Jalousie. 2003.(texto impresso em forma de apostila)

GREIMAS, Algirdas Julien. Du sens II: essais sémiotiques. Paris: Seuil, 1983.

GUÉRIOS, Rosário Farâni Mansur. Dicionário etimológico de nomes e sobrenomes. São Paulo: Ave Maria, 1981.

ROSA, João Guimarães. Tutaméia: terceiras estórias. Rio de Janeiro: José Olympio, 1967. 